\title{
Living with our machines: Towards a more sustainable future
}

Steven V. Ley, Yiding Chen, Daniel E. Fitzpatrick and Oliver S. May

Correspondence: Prof. Steven V. Ley

Email:svl1000@cam.ac.uk

Department of Chemistry, University of Cambridge, Lensfield Road, Cambridge, CB2 1EW, UK

\begin{abstract}
With illustrative examples from our laboratories, we make the case for how our digital and machine-based world is impacting on the assembly of our functional molecules in a more sustainable fashion.

Our equipment today is better able to deliver efficiencies through labour-saving methods, optimisation and scale-up, helping to minimise solvent usage, improve reaction telescoping and enhance other principles for process intensification. The machinery gives us confidence in safely handling reactive gases, exotherms and the other potentially hazardous events through remote control methods. Continuous flow chemistry processing plays a central role in delivering on this new holistic systems approach to synthesis.
\end{abstract}

\section{Keywords}

Machine Learning, Flow Chemistry, Reactive Gases

\section{Introduction}

In a review in 2012, ${ }^{[1]}$ we posed the question “On Being Green: Can Flow Chemistry Help?" Today we can comprehensively answer in the affirmative to this question thanks to the worldwide interest and intensity of the research activity in the area. ${ }^{[2-7]}$

While the aspirations of this early review are still relevant, we can go beyond its basic concepts to suggest collectively that our machine-assisted digital world is currently impacting widely on the assembly of our society's functional molecules. ${ }^{[8-9]}$ Robots, machine learning and artificial intelligence methods are becoming widespread and embracing all aspects of the synthesis process. ${ }^{[10]}$ Inevitably this plays a key role in the future sustainability of our discipline, particularly in developing on the Green Chemistry agenda. ${ }^{[1]}$

However, it is not easy to automate the process of organic synthesis, as the complexity and the extensive knowledge, and the necessary skill set in terms of mechanistic understanding, chemical reactivity, reagent choice and route selection, can be truly daunting.

It becomes even more of a problem, when we factor in all the practical aspects of downstream processing and unit operation methods needed to obtain pure products, such as chromatography, crystallisation, distillation, filtration, $\mathrm{pH}$ adjustment, water washing, solvent drying, evaporation and recycling. All this activity leads to larger waste streams, excessive solvent use and often poor energy management. While the machines around us can individually help to improve reaction robustness, safety, optimisation and analysis, ${ }^{[12]}$ data is often underutilised and tends to be siloed such that full exploitation rarely results. It is obvious therefore, in order to maximise the precious human resource, we need to better engage, understand and utilise our equipment in a holistic 
systems approach to synthesis. ${ }^{[13]}$

As flow chemistry technologies have already impacted widely ${ }^{[14-15]}$ on our science, it is not the purpose of this article to simply repeat the benefits that arise from using these methods, rather we will select topics, mainly from our own laboratories, that illustrate recent advances and principles which support adoption of a machine-driven approach towards a more sustainable future.

\section{Solvent 'Free' Reactions}

In synthesis, an obvious goal is to achieve the safe intensification of any process ${ }^{[16]}$ by reducing the size of an operating plant, greatly reducing the quantities of solvent used (ideally to no solvent) and minimising or preferably eliminating product work-up steps. On scale these parameters are of paramount importance. By contrast, academia is less constrained by these criteria, especially when working at the initial discovery level. We believe the climate is changing however, such that we need to accept greater responsibility for our actions. The drive to improve significantly and develop our enabling technologies through novel devices and efficiencies is therefore crucial.

In a program designed to test the capabilities of the HEL Flow CAT, as a small footprint, robust trickle-bed reactor, tolerant of high pressures and high temperatures, we investigated the reduction of ethyl nicotinate as a route to a primary building block for the preparation of the pharmaceutical agent $(R)$-Tiagabine. ${ }^{[17]}$

We found that ethyl nicotinate as a neat liquid could be directly processed through the reactor at $180{ }^{\circ} \mathrm{C}$ operating at 100 bar where it meets a hydrogen gas stream prior to exposure to a $5 \%$ $\mathrm{Rh} / \mathrm{Al}_{2} \mathrm{O}_{3}$ packed-bed catalyst. The resulting fully reduced product requires no downstream processing leading to a purity of material in excess of $96 \%$ and providing a stable throughput of $26.4 \mathrm{~g} \mathrm{~h}^{-1}$, equating to $639 \mathrm{~g} \mathrm{~d}^{-1}$ (Scheme 1)

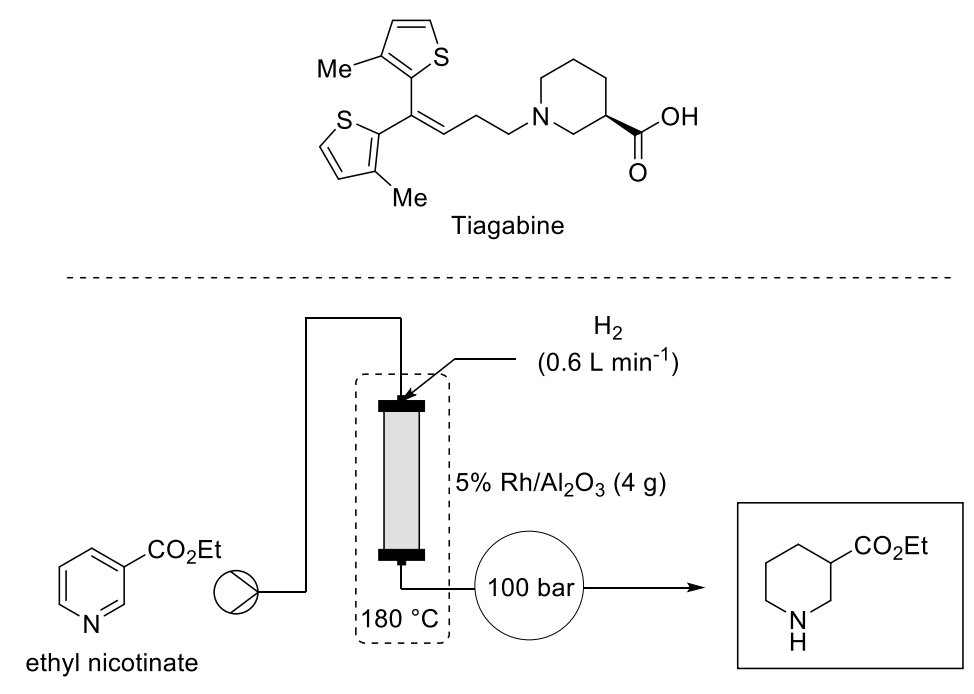

Scheme 1.

Pleased with this result we then progressed to a more challenging situation whereby we coordinated two linked sequential reactions employing conditions that, while successful under continuous flow processing, would have been deemed particularly hazardous using conventional batch-mode equipment. ${ }^{[18]}$

Here again it was necessary to introduce new equipment to access these high temperatures in a 
highly-controlled fashion. The approach required us to rapidly reach a high reaction temperature but not to overheat the system by sustained high temperatures, which would lead to degradation and polymerisation in a typical large-scale batch reaction.

For this process, the Thales Nano Phoenix flow reactor was selected as this employed inert Hastelloy reactor tubing capable of reaction temperatures in excess of $420^{\circ} \mathrm{C}$ and ideal for 'no solvent' reaction processing while maintaining the opportunity for intensification and directing the output into a second synthesis step. Once again this involved the HEL Flow CAT for progressing the neat product to a final material.

The first stage in this new reaction set-up required passage of neat allylated phenol briefly at $320^{\circ} \mathrm{C}$ through the Phoenix reactor to bring about a Claisen rearrangement. The pure intermediate product being collected into a receiving reservoir following in-line heat exchange to cool the sample. This product (unpurified) was then pumped, in the second step, to the HEL reactor at $210^{\circ} \mathrm{C}$ via a $20 \% \mathrm{Pd} / \mathrm{C}$ packed-steel tubing column to give the final alkylated cyclohexanone in high purity and available for further processing (Scheme 2). Clearly in terms of cost saving, efficiencies, precise reaction control and optimisation these new reactor configurations open up new opportunities and pave the way for new reaction discovery.

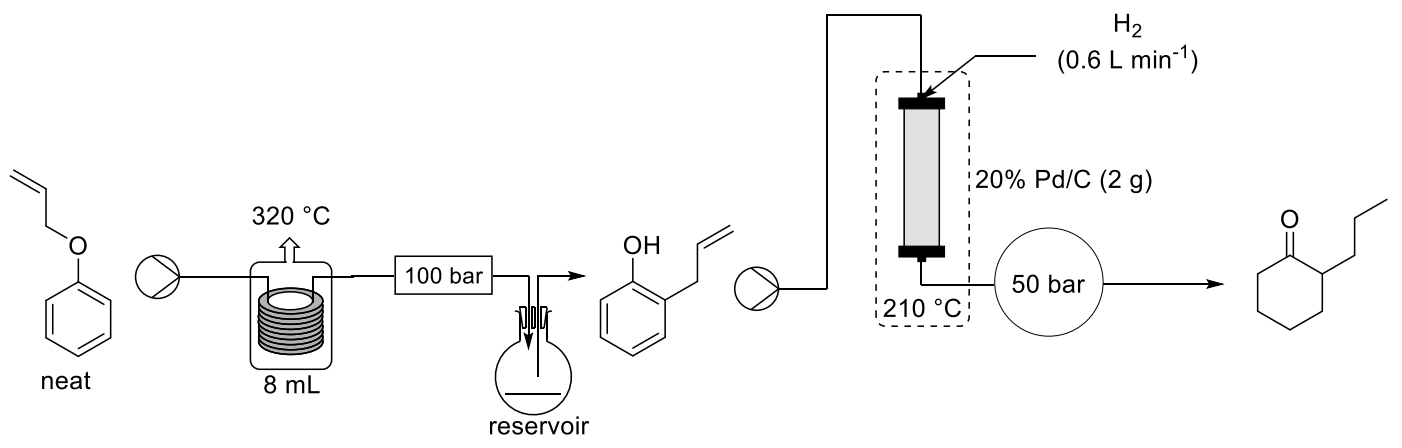

Scheme 2

For example, in a recent study we have utilised the high temperature Phoenix reactor in an interesting catalytic hydrogen borrowing transformation, whereby we coupled two neat chemical inputs namely amines with alcohols in the presence of a $\left[\mathrm{Ru}(p \text {-cymene }) \mathrm{Cl}_{2}\right]_{2}$ catalyst at $250{ }^{\circ} \mathrm{C} .{ }^{[19]}$ In a specific example (Scheme 3) morpholine was coupled with benzyl alcohol to give the corresponding aminated product with loss of water as the only by-product. Again, while the crude coupled product from a $9 \mathrm{~h}$ reaction run was isolable, we preferred to continuously transfer the neat material directly to a second reactor where it was mixed with $\mathrm{HCl}$ in dioxane through a modified T-piece on a Polar Bear Plus device to afford the final white crystalline hydrochloride salt. Following filtration and a brief washing cycle. In this way $1.2 \mathrm{~kg}$ of material was readily processed. The paper also describes many other examples including the preparation of Piribedil and Buspirone as pharmaceutically relevant drug substances. 


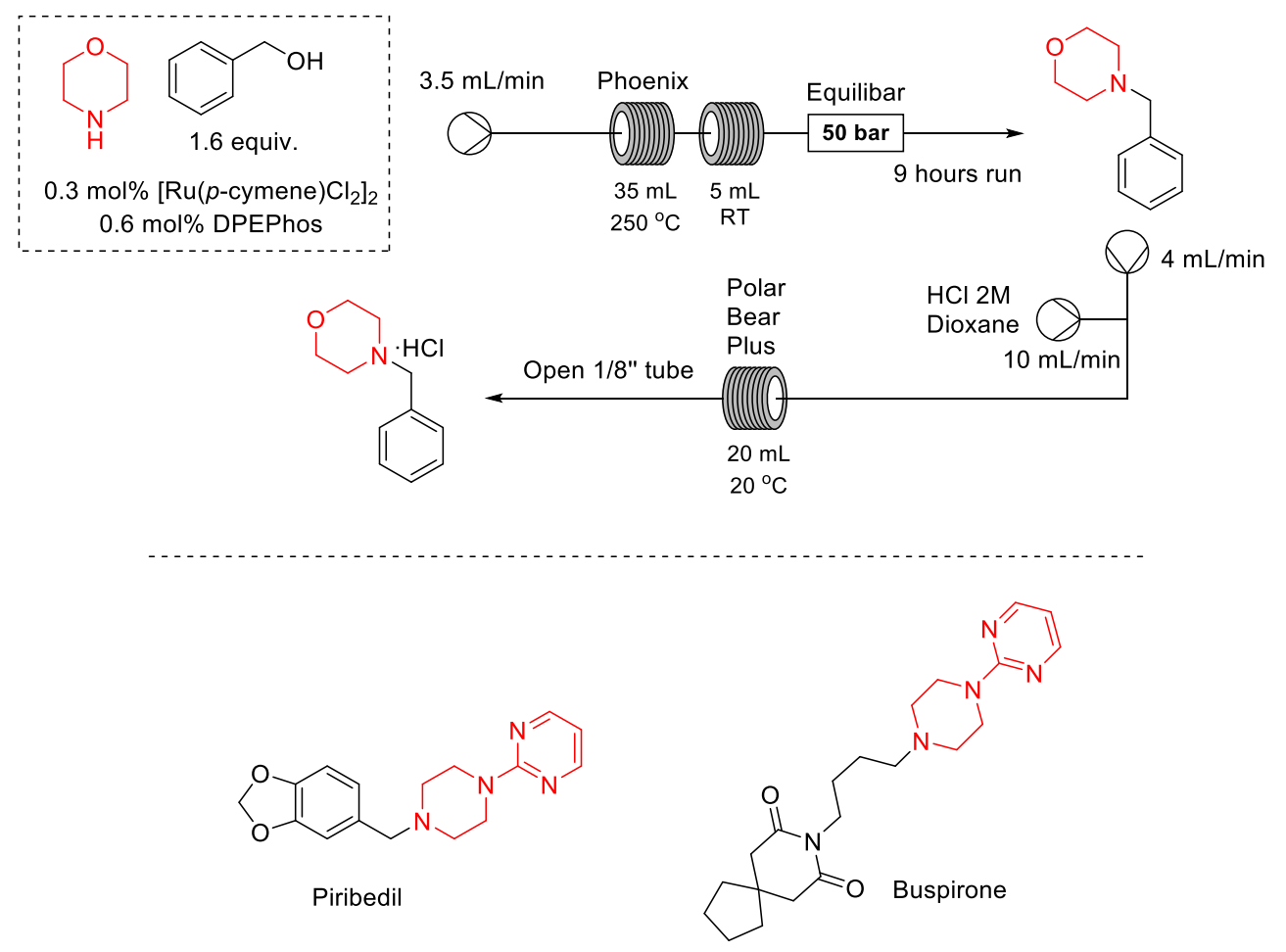

Scheme 3. By minimizing researcher involvement due to the machine contribution to the progress.

This work necessitated the adoption of an open-minded approach to synthesis where a bolder attitude led to real advances, both in terms of the required equipment but also by intensifying the process to minimise downstream work-up by avoiding the conventional use of an accompanying solvent.

\section{Use of Multiple-Gas Combinations in Synthesis}

The use of reactive gases in synthesis under conventional batch conditions is often associated with a range of practical issues that limit their use. Namely, the need for high pressure gas containment in cylinders or specially designed reaction vessels. Venting of excess, often toxic, gases and reaction exotherms are also common problems. In spite of these constraints, gases have green credentials in that they are easily removed at the end of a sequence such that reaction work-up is facilitated. Moreover, many reactive gases can be obtained or made cheaply, on scale and are especially attractive for usage under flow reaction regimes. Accordingly there is now a large volume of publications and reviews in this area, mostly describing application of a single gas. ${ }^{[20-22]}$

We will not reiterate this information here but we will comment only on the use of multiple gas reaction combinations in synthesis.

As a starting point, it would be useful if ethylene gas could be terminally differentiated on each end of the alkene selectively using two Heck reactions. This process would initially provide access to useful styrene building-blocks by a first coupling with aryl halide $\left(\operatorname{Ar}^{1} I\right)$ and subsequently via a second Heck process, with a different aryl iodide $\left(A r^{2} I\right)$, give the corresponding stilbenes as a final product but importantly without the need to add further catalyst at an intermediate stage (Scheme 4). 


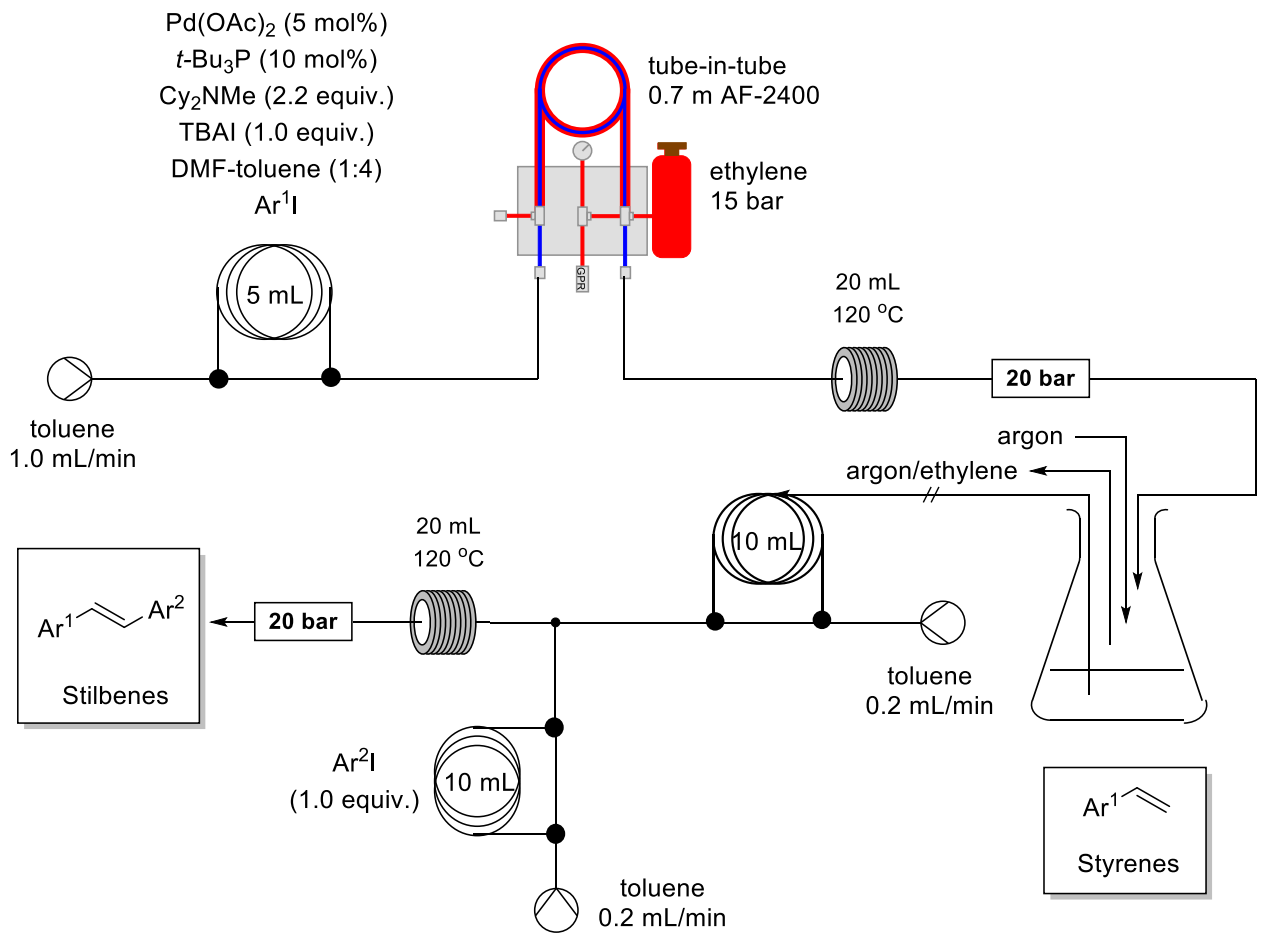

Scheme 4

In order to bring about these two distinct coupling transformations, the ethylene gas was delivered via a special tube-in-tube reactor developed previously ${ }^{[23]}$ for the accurate delivery of gases to flowing solutions. This unit makes use of a semi-permeable but chemically-inert Teflon AF2400 polymer tubing positioned within a larger diameter PTFE tube, thereby only exposing the reactor to a small volume of the reactive gas. The gas permeates into the flowing reaction stream via the inner tube to give a gas-rich reaction system tolerant of most gaseous materials.

In this specific application the aryl iodide and appropriate catalysts are mixed and flowed through the tube-in-tube reactor to react with the ethylene gas in the first external reaction coil operating at $120^{\circ} \mathrm{C}$. The output is collected, and excess ethylene simultaneously vented away using an Argon flush stream. Work-up at this point affords the styrene products (10 examples). However, if the crude product stream is mixed with a new aryl iodide a second Heck reaction can now occur, to give the corresponding stilbenes as the final product (Scheme 4). ${ }^{[24]}$

Following on from this work that we showed the initially produced styrenes could be further processed by employing another gas reaction to give branched aldehydes via a hydroformalyation sequence (Scheme 5). ${ }^{[25]}$ 


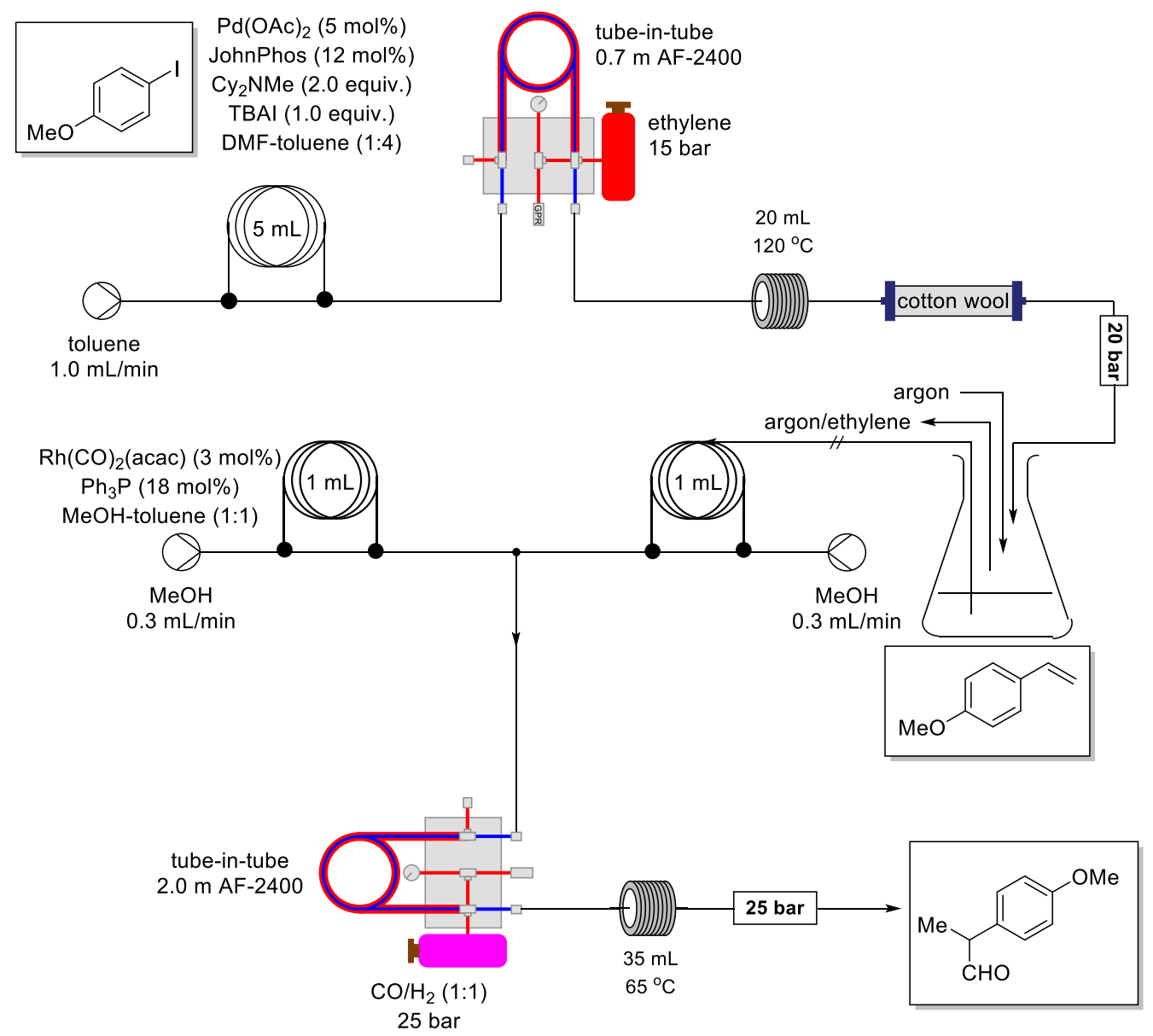

Scheme 5.

In this way, two further gases $\left(\mathrm{CO}, \mathrm{H}_{2}\right)$ are brought into play through a second tube-in-tube reactor such that overall the system consists of a triple gas reaction sequence. A full paper describing the opportunities of these multi-gas reactions has been reported. ${ }^{[26]}$ Of particular note in this work is a description of a machine-assisted work-up platform, fully linked to the above chemistries and automated using a camera viewing system ${ }^{[27]}$ to control an in-line liquid-liquid separation prior the isolation of pure products.

To further diversify the use of this ethylene gas reactor system for generating styrenes, it was coupled to an aerobic $\left(\mathrm{O}_{2}\right)$ anti-Markovnikov oxidation sequence to afford arylacetaldehydes as products. ${ }^{[28]} \mathrm{Here}$ the styrene precursors were introduced as mixtures with $(\mathrm{MeCN})_{2} \mathrm{PdCl}_{2}$ and $\mathrm{CuCl}_{2}$ as catalysts through a tube-in-tube reactor for $\mathrm{O}_{2}$ gas delivery. After passage through a $30 \mathrm{~mL}$ curing coil, the product was worked up in the normal way to deliver the corresponding arylacetaldehyde as the major product following anti-Markovnikov oxidation. Overall this process also constitutes a novel two-gas combination (ethylene, $\mathrm{O}_{2}$ ). The procedure featured as a key element in constructing the bisaryl fragment of Sacubitril, a component of CZ696 a first in class angiotensin II receptor blocker. This work is especially interesting in that a total of three gases (ethylene, $\mathrm{O}_{2}, \mathrm{H}_{2}$ ) were used in the preparation together with several other flow chemistry related steps. ${ }^{[29]}$ The reader is encouraged to consult this work for full details for these procedures.

Lastly in this section an interesting two gas combination using the tube-in-tube reactors has been reported. ${ }^{[30]}$ In this example aryl iodides are firstly carbonylated (with $\mathrm{CO}$ ) then subsequently 
aminated with a gaseous amine $\left(\mathrm{Me}_{2} \mathrm{NH}\right)$ to afford amides (Scheme 6).

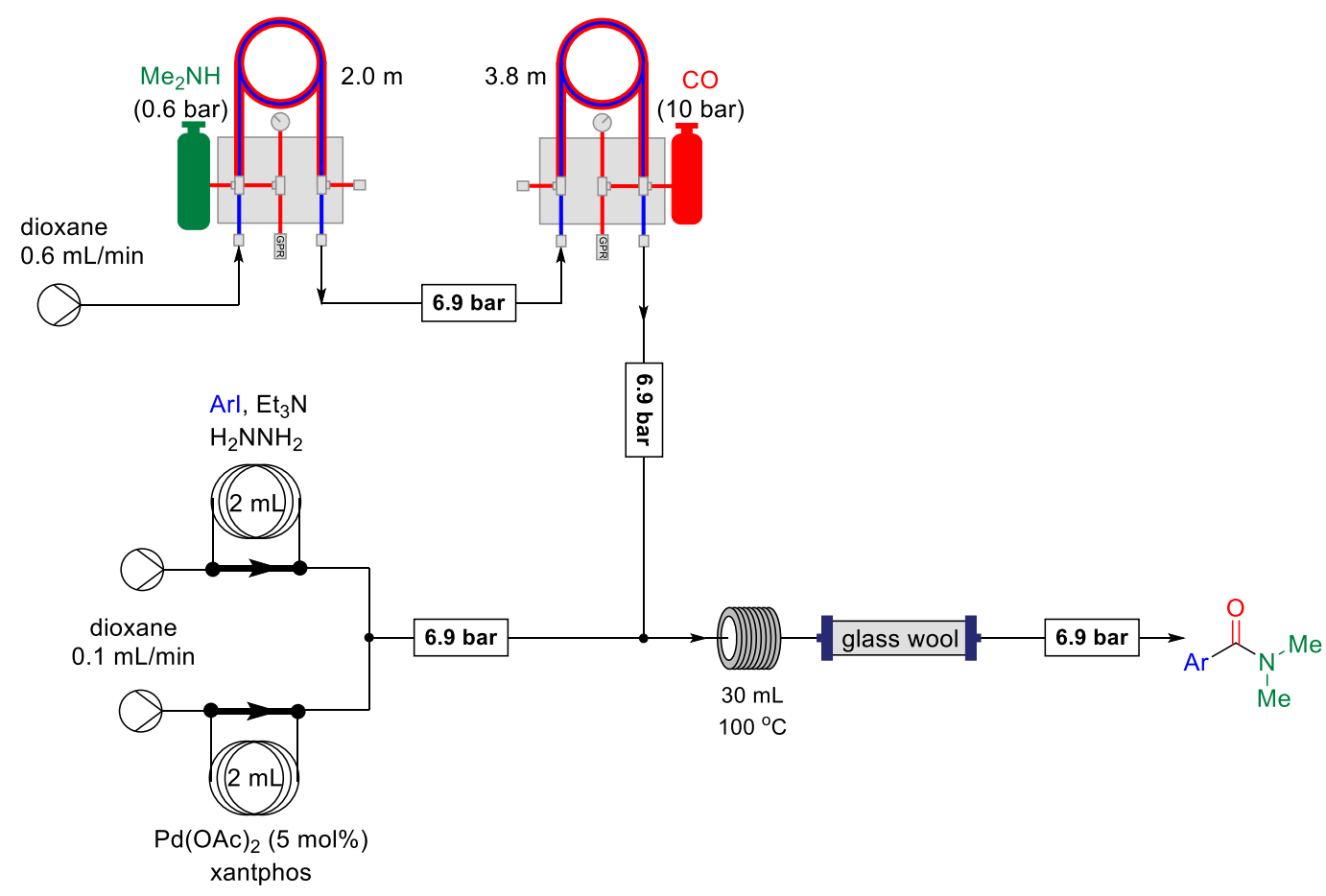

Scheme 6.

We can envision many more of these multi-gas combinations for application in synthesis and believe they have considerable merit in delivering machine-assisted clean telescoped chemical reactions in the future.

\section{Generation and Use of Hazardous Intermediates}

In spite of our general desire to work with less toxic and hazardous chemicals, the real world dictates otherwise. It is imperative therefore that we understand the problems that can arise and can manage potentially dangerous materials in a safe fashion with minimum risk of exposure. Use of any chemical to some extent present us with containment and monitoring issues. Indeed many of the molecules we make (at the time they are first prepared) have unknown properties and must be treated with considerable caution. ${ }^{[31]}$ The message is therefore clear: we need to improve greatly the practice of organic synthesis going forward especially where our machines will have an increasing role to play.

$\mathrm{We}^{[32]}$ and others ${ }^{[33-34]}$ have written extensively on this topic, and most notably on the use of flow chemistry and continuous processing methods to alleviate the problems of reliable generation and use of highly reactive substrates.

In this section, we will address just one opportunity from our own research which involves the generation, translocation and reaction of unstable diazo intermediates using flow chemistry methods.

Diazo compounds are well recognised to be highly reactive alkylating agents, unstable, toxic and explosive, yet can display very useful properties for constructing bonds that are difficult to make by other methods. Batch mode generation of reactive intermediates is nearly always associated with exothermic processes and other incompatibilities between reagents, conditions and products. 
However on moving to flow mode, one can compartmentalise the individual events and concoct a train of events that processes the material via discrete zones. How this concept works for the preparation of unstable diazo reactive intermediates involves an initial generation stage, in this case using an $\mathrm{MnO}_{2}$ cartridge to oxidise a hydrazone, which itself was generated separately in flow from a carbonyl compound, to give the corresponding diazo compound. This material is not isolated due to its known hazardous nature but is contained then translocated to a final reaction zone for coupling with a suitable partner. In this way there is no build-up of reactive material as shown by in-line IR methods and the information obtained is collected and used to control the whole reaction process.

As an application of this strategy in synthesis, various boronic acids react at room temperature to give a homologated product, which on protodeboronation, affords useful sp2-sp3 cross-coupled materials (Scheme 7). ${ }^{[35]}$
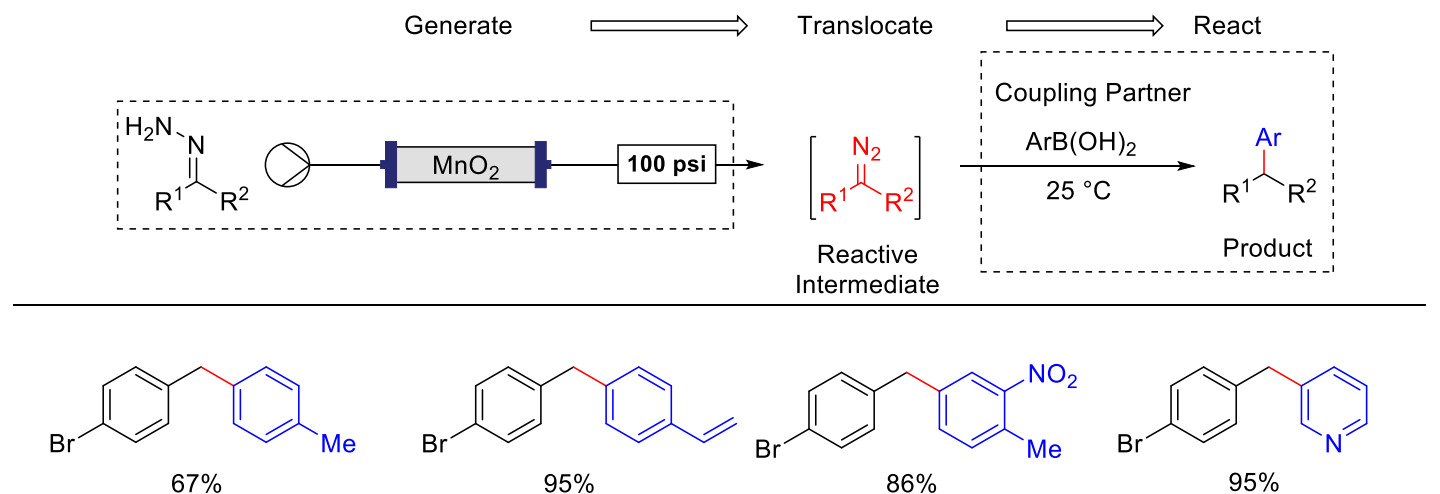<smiles>C=Cc1ccc(Cc2ccc(Br)cc2)cc1</smiles><smiles>Cc1ccc(Cc2ccc(Br)cc2)cc1[N+](=O)[O-]</smiles><smiles>Brc1ccc(Cc2cccnc2)cc1</smiles><smiles>CC(C)(C)Oc1cccc(Cc2ccc(Br)cc2)c1</smiles>

$69 \%$<smiles>CC(C)(C)C</smiles><smiles></smiles><smiles>COc1c(Cl)ccc(Cc2ccc(Br)cc2)c1F</smiles><smiles>Cc1ccc(Cc2cccc([N+](=O)[O-])c2)cc1</smiles><smiles>Clc1ccc(Cc2ccccc2)cc1</smiles><smiles>C=Cc1ccc(C/C=C(\C)CC/C=C(/C)[NH2+][Na])cc1</smiles><smiles>C=Cc1ccc(C(c2ccccc2)c2ccccc2)cc1</smiles>

+ Other examples

Scheme 7

The reaction displays wide functional group tolerance and owing to the mild, room temperature conditions by which the diazo species are generated, it was possible to intercept the unstable intermediate homologated boronic acids as their corresponding stable B(Pin) ester derivatives. After further iterations of these coupling reactions using up to three different diazo compounds, it was possible to generate molecular complexity through sequential $\mathrm{C}-\mathrm{C}$ bond forming processes (Scheme 8). ${ }^{[36]}$ 


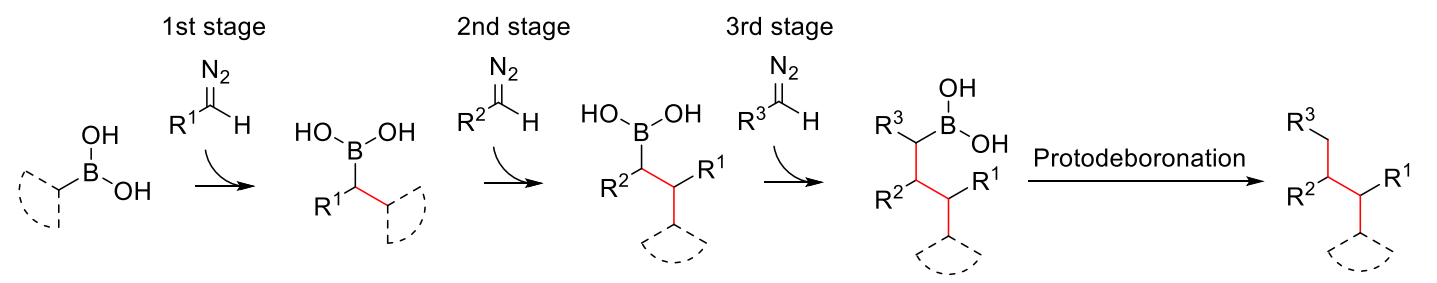

Examples of product homologation<smiles>CCC(c1cccc(OC)c1)C(Cc1cccnc1)c1cccc(OC)c1</smiles>

$37 \%$

( $72 \%$ yield average for each stage)<smiles>COc1cccc(C(Cc2cccnc2)C(c2cccc(OC)c2)C2CC2)c1</smiles>

$28 \%$

( $66 \%$ yield average for each stage)<smiles>COc1cccc(C(Cc2cccnc2)C(c2cccc(OC)c2)C(C)C)c1</smiles>

$30 \%$

( $68 \%$ yield average for each stage)

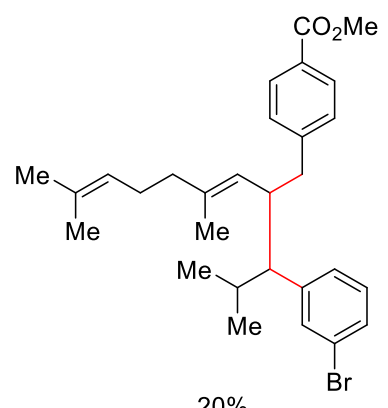

(59\% yield average for each stage)

Scheme 8.

Again these reactions demonstrate wide group compatibilities and nicely illustrate a new method for the sequential construction of new carbon-carbon bonds.

Also during this work we demonstrated that the flow-generated reactive intermediate diazo compounds can be used in other bond forming processes. For example, aminoacrylates were shown to react very rapidly at room temperature to directly afford the corresponding cyclopropanes mostly in excellent yields (Scheme 9a). ${ }^{[37]}$

A fully telescoped version of this new cyclopropanation procedure was also reported. Of note here is that the initial allylic alcohol was first converted in-line to an aldehyde by oxidation using an $\mathrm{MnO}_{2}$ cartridge. This was then reacted together in a vessel with hydrazine to give the hydrazone which could be separately pumped through a second $\mathrm{MnO}_{2}$ reactor (monitored by an in-line IR at the stretch signal around $2050 \mathrm{~cm}^{-1}$ featured in diazo groups), and subsequently coupled with the acrylate to give the cyclopropane in $66 \%$ overall telescoped yield (Scheme 9b). 


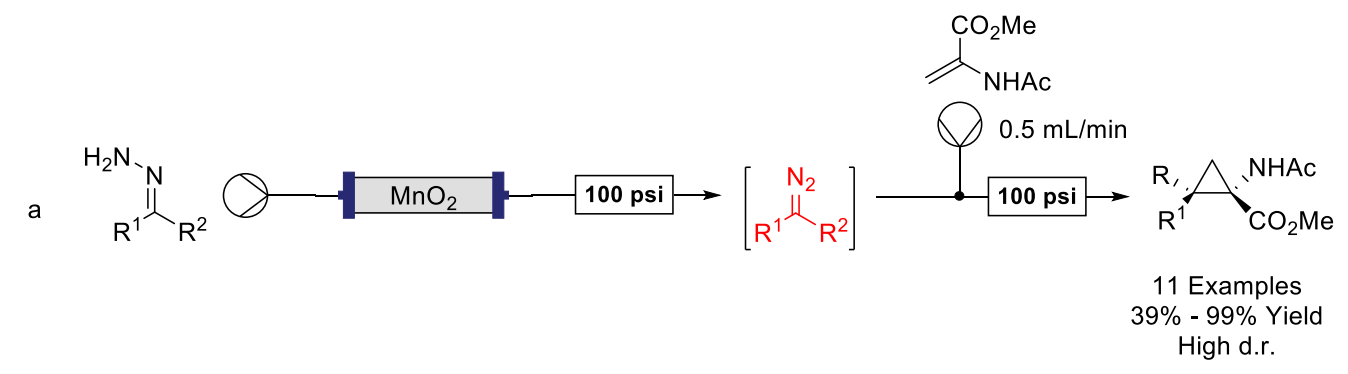<smiles>CC(C)=CCCC(C)=CCO</smiles>

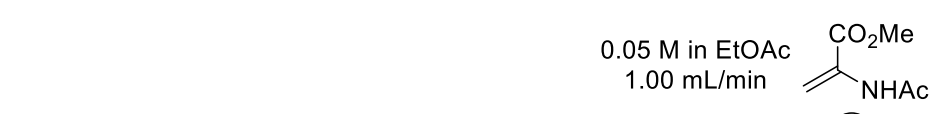

b

$0.2 \mathrm{M}$ in THF

$0.5 \mathrm{~mL} / \mathrm{min}$
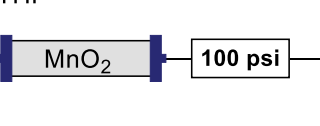

$1.0 \mathrm{~mL} / \mathrm{min}$

$\mathrm{N}_{2} \mathrm{H}_{4}$

(1.05 equiv.)

$1.00 \mathrm{~mL} / \mathrm{min}$

$\mathrm{NHAc}$

- 99\% Yield

High d.r.

stirred at $22{ }^{\circ} \mathrm{C}, 2 \mathrm{~h}$

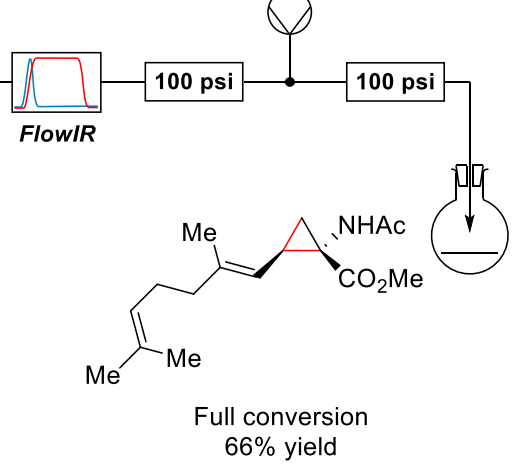

Scheme 9.

A route to di- and tri-substituted allenes from actylenes has also been developed via application of these flow-generated diazo species. These reactions were achieved through a copper catalysed process which notably occurred at room temperature and demonstrated broad reaction scope (Scheme 10). ${ }^{[38]}$

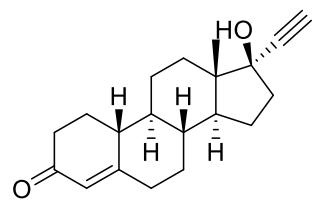

norethindrone
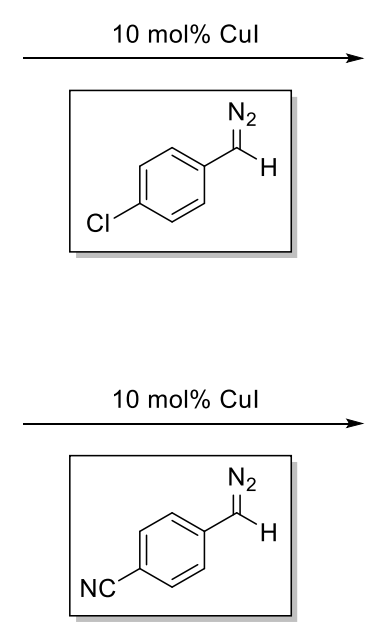

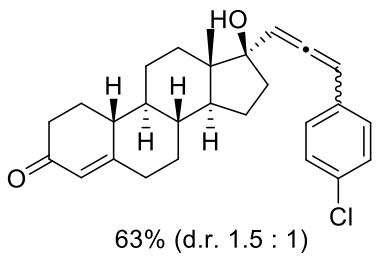

+35 other examples<smiles>C=CC1C2CN3CC1[C@@H](OCC=C=Cc1ccc(C#N)cc1)N3C2</smiles>

$82 \%$ (d.r. $1: 1)$

Scheme 10.

As further extension of this work, a new chiral copper catalyst for the asymmetric synthesis of propargylated amines using flow generated diazo compounds was discovered. As in the previous 
examples, the product of this coupling process demonstrated excellent functional group tolerance and was applied to a number of pharmaceutical agents (Scheme 11). ${ }^{[39]}$

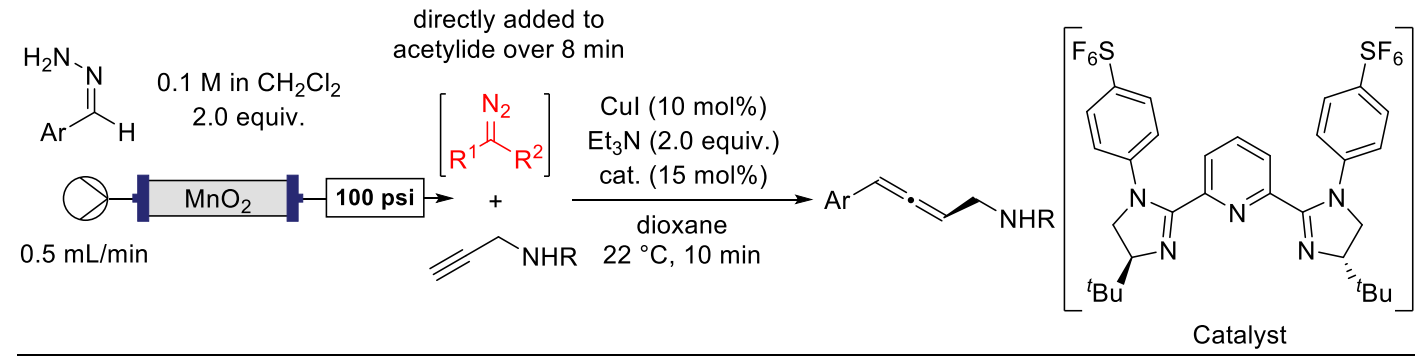

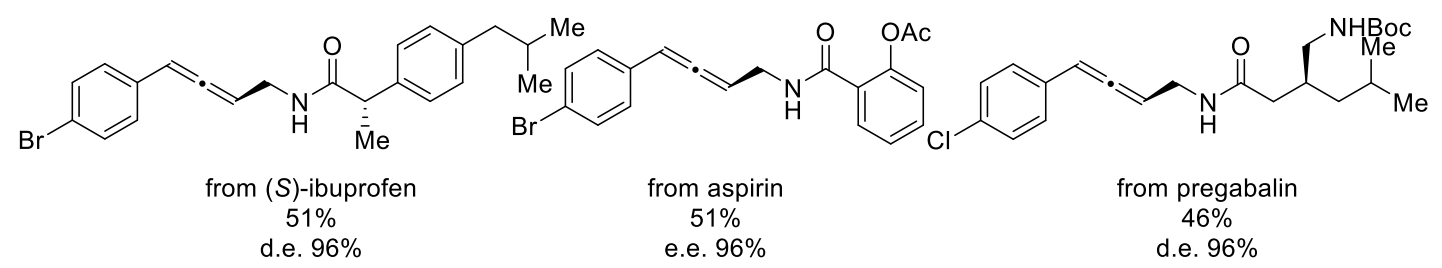<smiles>CC1(C)C[C@H](NC(=O)Cc2ccccc2)C(=O)N1C(=O)NC/C=C/c1ccc(Br)cc1</smiles>

from penicillin $\mathrm{G}$

$30 \%$

d.e. $98 \%$<smiles>CC(C)(C)OC1OC2COC(C)(C)OC2C1OCOS(=O)(=O)NC/C=C/c1ccc(Cl)cc1</smiles>

from topiramate

$57 \%$

d.e. $96 \%$<smiles>COc1ccc2c(c1)c(CC(=O)NCC=Cc1ccc(Br)cc1)c(C)n2C(=O)c1ccc(Cl)cc1</smiles><smiles>CC(C)c1c(C(=O)Nc2ccccc2)c(-c2ccccc2)c(-c2ccc(F)cc2)n1CCC1CC(CC(=O)NCC=Cc2ccc(Br)cc2)OC(C)(C)O1</smiles>

Scheme 11.

In spite of the considerable success above using diazo compounds in these new coupling processes, we sought alternative precursors to the thermally liable hydrazones. Work by Warkentin suggested the corresponding 1,3,4-oxadiazolines (also readily obtained from carbonyl compounds) are much more stable than hydrazones. And importantly, on UV irradiation, the 1,3,4-oxadiazolines afforded the corresponding diazo species in-situ. These can then go on to react with a variety of substrates (Scheme 12). ${ }^{[40]}$

For example, the oxadiazolines can be coupled at room temperature through their intermediate diazo species with boronic acids to effect a metal-free Csp2-Csp3 cross-coupling reaction leading eventually to protodeboronated or oxidised products depending upon the work-up conditions (Scheme 12). A large reaction scope was demonstrated for this process, and all reactions could be performed on an automated reactor platform to provide a useful series of chemical building blocks for synthesis. 


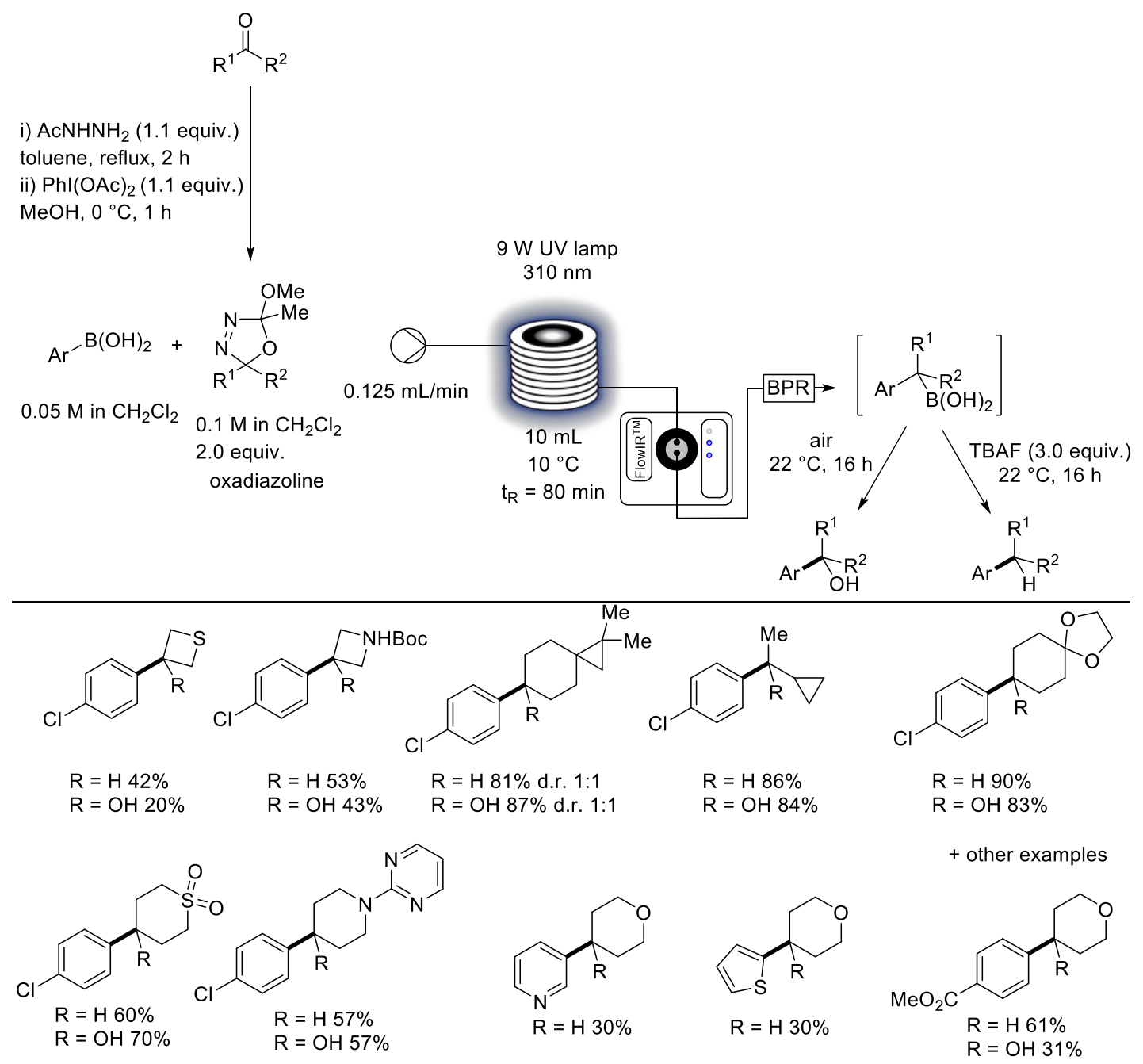

Scheme 12.

Alternatively, by reacting with vinyl boronic acids as the coupling partners, a three-component combination can be realised. Following a second coupling with aldehydes (or imines), multiplysubstituted homoallylic alcohols and amines are obtained as the final products. ${ }^{[1]}$ Alternatively, if these useful oxadiazoline precursors are mixed with aldehydes and irradiated with a UV photoreactor direct $\mathrm{C}-\mathrm{H}$ functionalisation occurs in good yields to form a product with a new $\mathrm{C}$ - $\mathrm{C}$ bond (Scheme 13). Again a wide functional group tolerance was observed. ${ }^{[42]}$ 


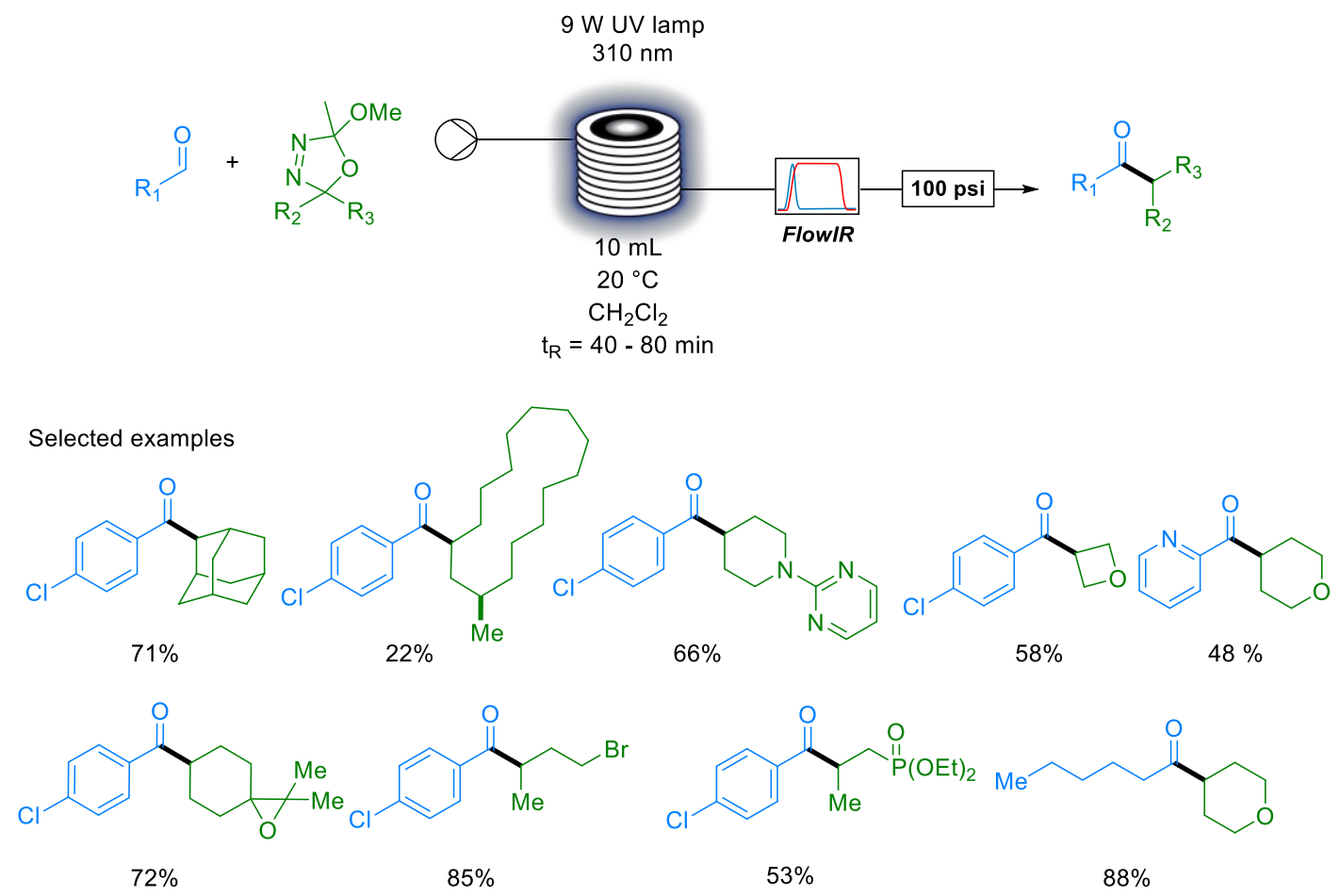

Scheme 13.

Finally as another useful example of this machine-assisted flow chemistry approach, oxadiazolines were employed in a direct coupling with aqueous formaldehyde. The homologated product could be further diversified to benzimidazoles or, on reduction, to alcohols. Again these reactions provide access to materials often difficult to obtain by more conventional chemistry. ${ }^{[43]}$

\section{Telescoping Multistep Syntheses}

Telescoping machines together has been a long-standing area of interest in our group and was underpinned with the desire to conduct multistep synthesis sequences without the typical repetitive labor and time-consuming work-up tasks common to conventional synthesis programmes. ${ }^{[44]}$

Initial success came through the use of immobilised reagents and impurity scavenging systems. These reagents were made using polymer beads as supporting agents which can be removed at the end of the reaction by filtration or physically with tweezers to remove a porous pouch that contains the immobilised reagents ("tea bag" approach). In this way, reactions are progressed to the next synthesis step without the usual intermediate downstream purification stage common to traditional batch chemistry methods. Using these concepts there was a considerable saving in labor and also resulted in lower solvent using, avoiding chromatography and thereby generating far less waste. Many of these immobilised reagents can also be recovered and recycled which is also beneficial to synthesis programs. With these enabling methods available, complex natural products $^{[45]}$ and medicinally relevant materials ${ }^{[46]}$ were readily assembled. Since the technology is also readily automated, it becomes the perfect partner for telescoping flow reactor systems together. ${ }^{[47]}$

However we recognised that these flow chemistry platforms could provide even greater opportunities beyond their simple use of reagent immobilisation and in-line work-up, by for 
example in their ability to control exotherms, or high temperatures and high pressures. Equally, access to lower temperatures without the use of traditional cryogens is an attractive feature of the devices. ${ }^{[48]}$ Also since these flow systems operate in a contained environment, this improves safety, especially when handling hazardous materials (see earlier section). Moreover, reaction robustness and reproducibility arise through application of various machine-learning algorithms.

There are now many examples of multistep flow reaction sequences which have been well reported and reviewed. ${ }^{[49-50]}$ We have therefore selected just two cases from our portfolio of telescoped reaction procedures to illustrate two main aspects, one of equipment development and the other of hazardous reaction containment.

The first of these employed a new peristaltic pumping device to drive three independent pumps on a single reactor platform ( $A, B$ and $C$ ) to add components through two PFA pre-cooling coils (PC1 and PC-2) which together combine to generate an aryllithium species in the first reactor coil (RC1). Pump $C$ then delivers the coupling carbonyl agent through the pre-cooled coil (PC-3) to react with the aryllithium species in a quench coil (QC-1). All these 5 coils are housed within a separate cooling device mounted on the reactor block at $-50^{\circ} \mathrm{C}$.

Next the flowing reaction steam is warmed to $30^{\circ} \mathrm{C}$ in the reactor coil RC-2 after which it is mixed and introduced on RC-3 to a stream of trifluoroacetic anhydride (TFAA) at room temperature $\left(22^{\circ} \mathrm{C}\right)$. The exiting reaction stream on further mixing with triethylamine undergoes elimination by passage through two reactor coils (RC-4 and RC-5) operating at $100{ }^{\circ} \mathrm{C}$ to afford the pharmaceutical agent Tamoxifen (a front-line drug for treating breast cancer). This is formed at a rate of 12.42 grams over an initial 80-minute reaction time, equating to 10,000 doses of drug substance per working day on a single small-footprint reactor platform (Scheme 14). ${ }^{[1]}$
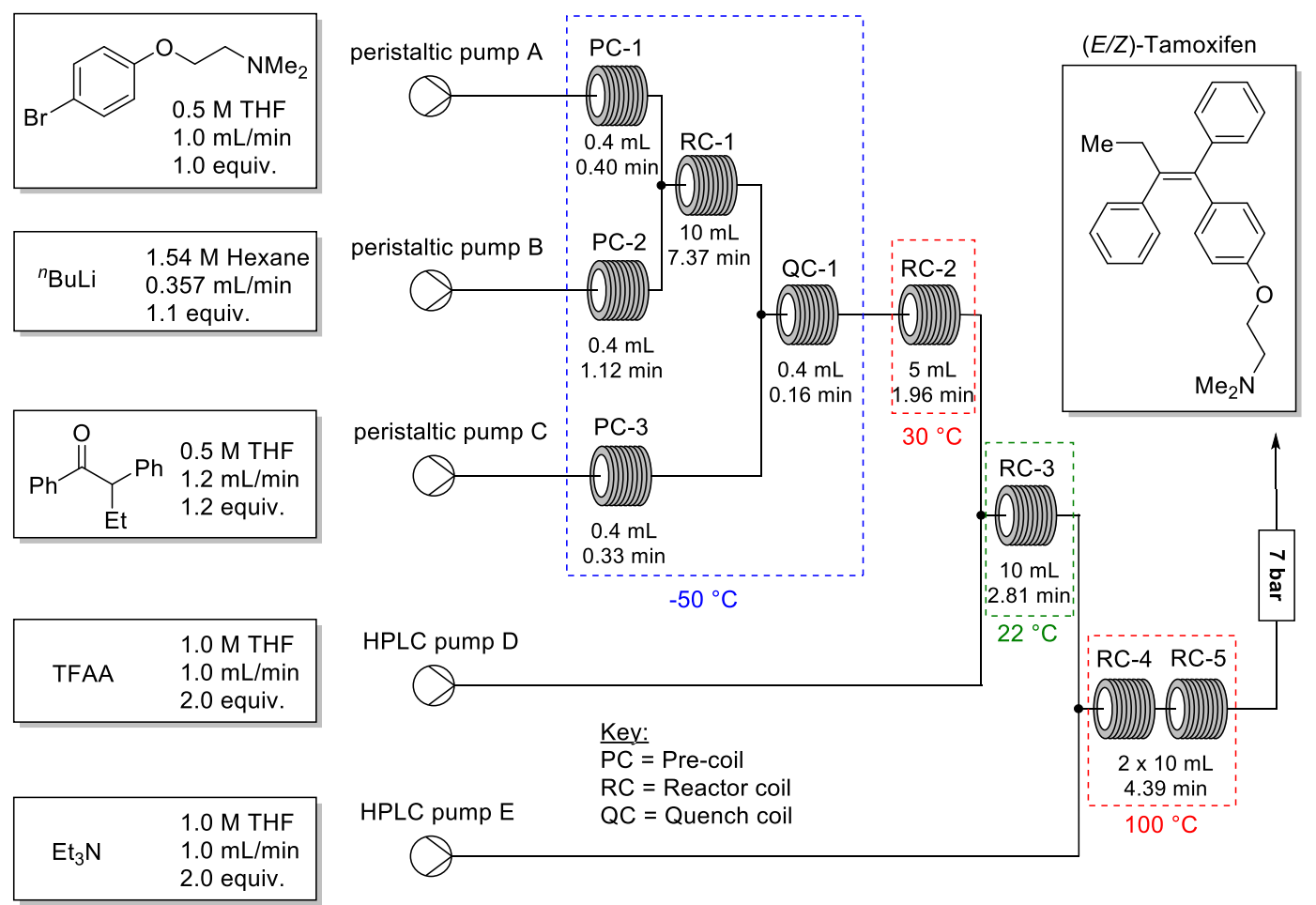

Scheme 14.

The final example reports a convergent multistep telescoped process for the preparation of a herbicidal agent. ${ }^{[52]}$ Here the reader should note especially the use and safe containment of very 
toxic and hazardous agents such as dimethyl sulfate and elemental bromine. Also, many of the intermediate products in this sequence were known to be hazardous species such that their use on scale during equivalent batch reactions would not be acceptable. Interestingly this telescoped route employs a camera-monitoring system, an in-line flow static mixer and followed by NMR and IR monitoring. A computer-controlled in-line $\mathrm{pH}$ adjustment also ensured a robust process. The final oxime product was obtained on scale and in high overall yield (Scheme 15).

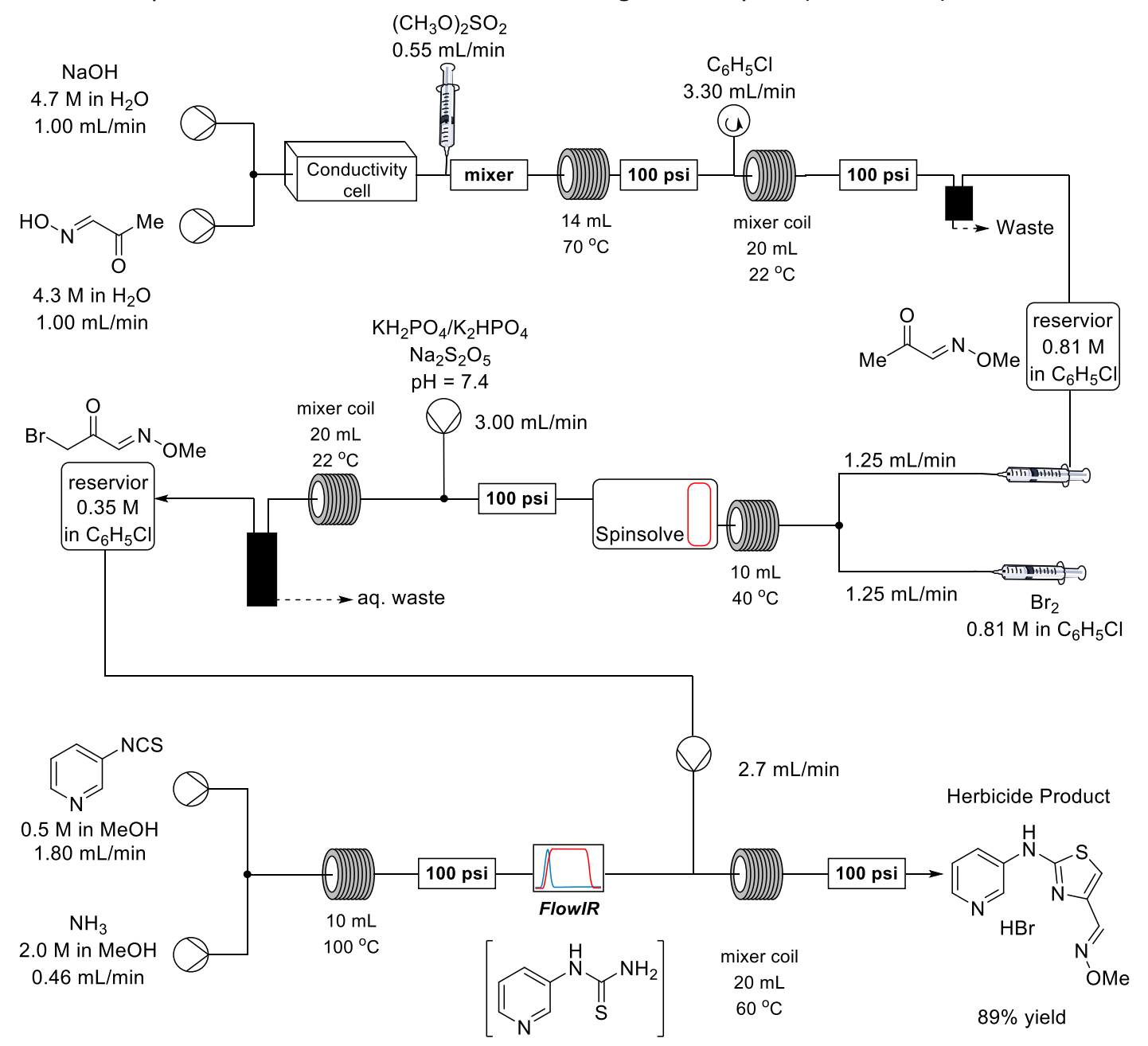

Scheme 15

\section{Summary and Perspective}

Examples from our laboratories reported above are chosen to illustrate the opportunities for synthesis by application of machine-assisted technologies. These have been selected to address many of important principles associated with the Green Agenda. Normally in synthesis programs there is an emphasis on discovery of improved methodology, however increasingly the development of the tools of synthesis using machines learning ${ }^{[53-56]}$ and artificial intelligence (Al) are becoming important. Saving the human resource is as crucial, going into the future, as saving our chemical resources. Better waste and energy management, especially by reducing solvents and downstream processing, will become primary drivers for process intensification through reaction telescoping. Relegating the repetitive events of scale-up and optimisation or by containing hazardous chemical transformations, our equipment is now playing a pivotal role and our digital world is evolving rapidly, we must therefore learn to live in harmony with our machines. 


\section{References:}

[1] S. V. Ley, On Being Green: Can Flow Chemistry Help?, Chem. Rec. 12 (2012) 378-390.

[2] D. Dallinger, C. O. Kappe, Why flow means green - Evaluating the merits of continuous processing in the context of sustainability, Curr. Opin. Green Sustain. Chem. 7 (2017) 6-12. A useful statement on green chemical processing.

[3] B. P. Mason, K. E. Price, J. L. Steinbacher, A. R. Bogdan, D. T. McQuade, Greener Approaches to Organic Synthesis Using Microreactor Technology, Chem. Rev. 107 (2007) 2300-2318.

[4] L. Rogers, K. F. Jensen, Continuous manufacturing - the Green Chemistry promise?, Green Chem. 21 (2019) 3481-3498. An important contribution to green chemistry flow processing.

[5] S. G. Newman, K. F. Jensen, The role of flow in green chemistry and engineering, Green Chem. 15 (2013) 1456-1472.

[6] S. V. Ley, D. E. Fitzpatrick, R. J. Ingham, R. M. Myers, Organic Synthesis: March of the Machines, Angew. Chem. Int. Edit. 54 (2015) 3449-3464. A key reference to machines in synthesis.

[7] D. E. Fitzpatrick, C. Battilocchio, S. V. Ley, Enabling Technologies for the Future of Chemical Synthesis, ACS Cent. Sci. 2 (2016) 131-138. A useful summary of future application in chemical synthesis.

[8] M. Trobe, M. D. Burke, The Molecular Industrial Revolution: Automated Synthesis of Small Molecules, Angew. Chem. Int. Edit. 57 (2018) 4192-4214.

[9] S. Steiner, J. Wolf, S. Glatzel, A. Andreou, J. M. Granda, G. Keenan, T. Hinkley, G. AragonCamarasa, P. J. Kitson, D. Angelone, L. Cronin, Organic synthesis in a modular robotic system driven by a chemical programming language, Science. 363 (2019) eaav2211.

[10] M. B. Plutschack, B. Pieber, K. Gilmore, P. H. Seeberger, The Hitchhiker's Guide to Flow Chemistry, Chem. Rev. 117 (2017) 11796-11893. A useful and extensive review of the area.

[11] R. A. Sheldon, The E Factor: fifteen years on, Green Chem. 9 (2007) 1273-1283.

[12] D. E. Fitzpatrick, C. Battilocchio, S. V. Ley, A Novel Internet-Based Reaction Monitoring, Control and Autonomous Self-Optimization Platform for Chemical Synthesis, Org. Process Res. Dev. 20 (2016) 386-394.

[13] R. J. Ingham, C. Battilocchio, D. E. Fitzpatrick, E. Sliwinski, J. M. Hawkins, S. V. Ley, A Systems Approach towards an Intelligent and Self-Controlling Platform for Integrated Continuous Reaction Sequences, Angew. Chem. Int. Edit. 54 (2015) 144-148.

[14] D. E. Fitzpatrick, S. V. Ley, Engineering chemistry for the future of chemical synthesis, Tetrahedron. 74 (2018) 3087-3100. Introductary paper to a symposium in print on the use of machines in synthesis.

[15] S. V. Ley, D. E. Fitzpatrick, R. M. Myers, C. Battilocchio, R. J. Ingham, Machine-Assisted Organic Synthesis, Angew. Chem. Int. Edit. 54 (2015) 10122-10136.

[16] J. C. Etchells, Process Intensification: Safety Pros and Cons, Process Saf. Environ. 83 (2005) 8589.

[17] T. Ouchi, C. Battilocchio, J. M. Hawkins, S. V. Ley, Process Intensification for the Continuous Flow Hydrogenation of Ethyl Nicotinate, Org. Process Res. Dev. 18 (2014) 1560-1566.

[18] T. Ouchi, R. J. Mutton, V. Rojas, D. E. Fitzpatrick, D. G. Cork, C. Battilocchio, S. V. Ley, SolventFree Continuous Operations Using Small Footprint Reactors: A Key Approach for Process Intensification, ACS Sustain. Chem. Eng. 4 (2016) 1912-1916.

[19] R. Labes, C. Mateos, C. Battilocchio, Y. Chen, P. Dingwall, G. R. Cumming, J. A. Rincón, M. J. Nieves-Remacha, S. V. Ley, Fast continuous alcohol amination employing a hydrogen borrowing 
protocol, Green Chem. 21 (2019) 59-63.

[20] M. Brzozowski, M. O’Brien, S. V. Ley, A. Polyzos, Flow Chemistry: Intelligent Processing of GasLiquid Transformations Using a Tube-in-Tube Reactor, Accounts. Chem. Res. 48 (2015) 349-362. An important review on the use of gases using membarne techonologies.

[21] C. J. Mallia, I. R. Baxendale, The Use of Gases in Flow Synthesis, Org. Process Res. Dev. 20 (2016) 327-360.

[22] A. Günther, K. F. Jensen, Multiphase microfluidics: from flow characteristics to chemical and materials synthesis, Lab Chip. 6 (2006) 1487-1503.

[23] M. O'Brien, N. Taylor, A. Polyzos, I. R. Baxendale, S. V. Ley, Hydrogenation in flow: Homogeneous and heterogeneous catalysis using Teflon AF-2400 to effect gas-liquid contact at elevated pressure, Chem. Sci. 2 (2011) 1250-1257.

[24] S. L. Bourne, P. Koos, M. O’Brien, B. Martin, B. Schenkel, I. R. Baxendale, S. V. Ley, The Continuous-Flow Synthesis of Styrenes Using Ethylene in a Palladium-Catalysed Heck Cross-Coupling Reaction, Synlett. 2011 (2011) 2643-2647.

[25] S. Kasinathan, S. L. Bourne, P. Tolstoy, P. Koos, M. O’Brien, R. W. Bates, I. R. Baxendale, S. V. Ley, Syngas-Mediated C-C Bond Formation in Flow: Selective Rhodium-Catalysed Hydroformylation of Styrenes, Synlett. 2011 (2011) 2648-2651. The first example of a triple-gas reaction in flow synthesis.

[26] S. L. Bourne, M. O'Brien, S. Kasinathan, P. Koos, P. Tolstoy, D. X. Hu, R. W. Bates, B. Martin, B. Schenkel, S. V. Ley, Flow Chemistry Syntheses of Styrenes, Unsymmetrical Stilbenes and Branched Aldehydes, ChemCatChem. 5 (2013) 159-172.

[27] S. V. Ley, R. J. Ingham, M. O’Brien, D. L. Browne, Camera-enabled techniques for organic synthesis, Beilstein J. Org. Chem. 9 (2013) 1051-1072.

[28] S. L. Bourne, S. V. Ley, A Continuous Flow Solution to Achieving Efficient Aerobic AntiMarkovnikov Wacker Oxidation, Adv. Synth. Catal. 355 (2013) 1905-1910.

[29] S.-H. Lau, S. L. Bourne, B. Martin, B. Schenkel, G. Penn, S. V. Ley, Synthesis of a Precursor to Sacubitril Using Enabling Technologies, Org. Lett. 17 (2015) 5436-5439.

[30] U. Gross, P. Koos, M. O'Brien, A. Polyzos, S. V. Ley, A General Continuous Flow Method for Palladium Catalysed Carbonylation Reactions Using Single and Multiple Tube-in-Tube Gas-Liquid Microreactors, Eur. J. Org. Chem. 2014 (2014) 6418-6430.

[31] S. P. Green, K. M. Wheelhouse, A. D. Payne, J. P. Hallett, P. W. Miller, J. A. Bull, Thermal Stability and Explosive Hazard Assessment of Diazo Compounds and Diazo Transfer Reagents, Org. Process Res. Dev. 24 (2020) 67-84.

[32] M. Movsisyan, E. I. P. Delbeke, J. K. E. T. Berton, C. Battilocchio, S. V. Ley, C. V. Stevens, Taming hazardous chemistry by continuous flow technology, Chem. Soc. Rev. 45 (2016) 4892-4928.

[33] B. J. Deadman, S. G. Collins, A. R. Maguire, Taming Hazardous Chemistry in Flow: The Continuous Processing of Diazo and Diazonium Compounds, Chem.: Eur. J. 21 (2015) 2298-2308.

[34] B. Gutmann, C. O. Kappe, Forbidden chemistries go flow in API synthesis, Chim. Oggi-Chem. Today. 33 (2015) 18-24.

[35] D. N. Tran, C. Battilocchio, S.-B. Lou, J. M. Hawkins, S. V. Ley, Flow chemistry as a discovery tool to access sp2-sp3 cross-coupling reactions via diazo compounds, Chem. Sci. 6 (2015) 1120-1125.

[36] C. Battilocchio, F. Feist, A. Hafner, M. Simon, D. N. Tran, D. M. Allwood, D. C. Blakemore, S. V. Ley, Iterative reactions of transient boronic acids enable sequential $\mathrm{C}-\mathrm{C}$ bond formation, Nat. Chem. 8 (2016) 360-367. 
[37] N. M. Roda, D. N. Tran, C. Battilocchio, R. Labes, R. J. Ingham, J. M. Hawkins, S. V. Ley, Cyclopropanation using flow-generated diazo compounds, Org. Biomol. Chem. 13 (2015) 2550-2554.

[38] J.-S. Poh, D. N. Tran, C. Battilocchio, J. M. Hawkins, S. V. Ley, A Versatile Room-Temperature Route to Di- and Trisubstituted Allenes Using Flow-Generated Diazo Compounds, Angew. Chem. 127 (2015) 8031-8034.

[39] J.-S. Poh, S. Makai, T. von Keutz, D. N. Tran, C. Battilocchio, P. Pasau, S. V. Ley, Rapid Asymmetric Synthesis of Disubstituted Allenes by Coupling of Flow-Generated Diazo Compounds and Propargylated Amines, Angew. Chem. Int. Edit. 56 (2017) 1864-1868.

[40] A. Greb, J.-S. Poh, S. Greed, C. Battilocchio, P. Pasau, D. C. Blakemore, S. V. Ley, A Versatile Route to Unstable Diazo Compounds via Oxadiazolines and their Use in Aryl-Alkyl Cross-Coupling Reactions, Angew. Chem. Int. Edit. 56 (2017) 16602-16605.

[41] Y. Chen, D. C. Blakemore, P. Pasau, S. V. Ley, Three-Component Assembly of Multiply Substituted Homoallylic Alcohols and Amines Using a Flow Chemistry Photoreactor, Org. Lett. 20 (2018) 65696572 .

[42] P. Dingwall, A. Greb, L. N. S. Crespin, R. Labes, B. Musio, J.-S. Poh, P. Pasau, D. C. Blakemore, S. V. Ley, C-H functionalisation of aldehydes using light generated, non-stabilised diazo compounds in flow, Chem. Commun. 54 (2018) 11685-11688.

[43] Y. Chen, M. Leonardi, P. Dingwall, R. Labes, P. Pasau, D. C. Blakemore, S. V. Ley, Photochemical Homologation for the Preparation of Aliphatic Aldehydes in Flow, J. Org. Chem. 83 (2018) 15558-15568. [44] S. V. Ley, D. L. Browne, M. O’Brien, 9 Immobilized Reagents and Multistep Processes, in: T. F. Jamison, G. Koch (Eds.), Flow Chemistry in Organic Synthesis, Georg Thieme Verlag, Stuttgart, 2018, pp. 273-312. A leading reference to the use of immobilized reagents in multistep synthesis.

[45] S. V. Ley, I. R. Baxendale, R. M. Myers, The Use of Polymer Supported Reagents and Scavengers in the Synthesis of Natural Products, in: A. M. Boldi (Eds.), Combinatorial Synthesis of Natural ProductBased Libraries, CRC Press, Boca-Raton, Florida, USA, 2006, pp. 131-163.

[46] I. R. Baxendale, S. V. Ley, in 'New Avenues to Efficient Chemical Synthesis', Eds. P. H. Seeberger, T. Blume, Springer Berlin Heidelberg, 2007, p. 151-185.

[47] S. V. Ley, I. R. Baxendale, R. N. Bream, P. S. Jackson, A. G. Leach, D. A. Longbottom, M. Nesi, J. S. Scott, R. I. Storer, S. J. Taylor, Multi-step organic synthesis using solid-supported reagents and scavengers: a new paradigm in chemical library generation, J. Chem. Soc. Perk. T. 1. (2000) 3815 4195.

[48] J. A. Newby, D. W. Blaylock, P. M. Witt, J. C. Pastre, M. K. Zacharova, S. V. Ley, D. L. Browne, Design and Application of a Low-Temperature Continuous Flow Chemistry Platform, Org. Process Res. Dev. 18 (2014) 1211-1220.

[49] H. R. Sahoo, J. G. Kralj, K. F. Jensen, Multistep Continuous-Flow Microchemical Synthesis Involving Multiple Reactions and Separations, Angew. Chem. Int. Edit. 46 (2007) 5704-5708.

[50] D. T. McQuade, P. H. Seeberger, Applying Flow Chemistry: Methods, Materials, and Multistep Synthesis, J. Org. Chem. 78 (2013) 6384-6389.

[51] P. R. D. Murray, D. L. Browne, J. C. Pastre, C. Butters, D. Guthrie, S. V. Ley, Continuous FlowProcessing of Organometallic Reagents Using an Advanced Peristaltic Pumping System and the Telescoped Flow Synthesis of (E/Z)-Tamoxifen, Org. Process Res. Dev. 17 (2013) 1192-1208. An impressive example of a drug substance synthesis.

[52] E. Godineau, C. Battilocchio, M. Lehmann, S. V. Ley, R. Labes, L. Birnoschi, S. Subramanian, C. S. Prasanna, A. Gorde, M. Kalbagh, V. Khade, A. Scherrer, A. C. O’Sullivan, A Convergent Continuous 
Multistep Process for the Preparation of C4-Oxime-Substituted Thiazoles, Org. Process Res. Dev. 22 (2018) 955-962.

[53] A. M. Schweidtmann, A. D. Clayton, N. Holmes, E. Bradford, R. A. Bourne, A. A. Lapkin, Machine learning meets continuous flow chemistry: Automated optimization towards the Pareto front of multiple objectives, Chem. Eng. J. 352 (2018) 277-282.

[54] A. D. Clayton, A. M. Schweidtmann, G. Clemens, J. A. Manson, C. J. Taylor, C. G. Niño, T. W. Chamberlain, N. Kapur, A. J. Blacker, A. A. Lapkin, R. A. Bourne, Automated self-optimisation of multistep reaction and separation processes using machine learning, Chem. Eng. J. 384 (2020) 123340. A topical report on machine-learning.

[55] T. Badowski, E. P. Gajewska, K. Molga, B. A. Grzybowski, Synergy Between Expert and MachineLearning Approaches Allows for Improved Retrosynthetic Planning, Angew. Chem. Int. Edit. 59 (2020) 725-730. A recent and important publication on machine-assisted synthesis planning.

[56] M. H. S. Segler, M. Preuss, M. P. Waller, Planning chemical syntheses with deep neural networks and symbolic AI, Nature. 555 (2018) 604-610. 